\title{
Mobile phone use among children and its impact on hearing: Our experience at a tertiary care teaching hospital
}

\author{
Santosh Kumar Swain', Ishwar Chandra Behera², Mahesh Chandra Sahu³ , Jasashree Choudhury ${ }^{4}$ \\ 'Department of Otorhinolaryngology, IMS and SUM Hospital, Siksha "O" Anusandhan University, K8, Kalinganagar, \\ Bhubaneswar, Odisha, India \\ 2Department of Community Medicine, IMS and SUM Hospital, Siksha "O" Anusandhan University, K8, Kalinganagar, \\ Bhubaneswar, Odisha, India \\ ${ }^{3}$ Directorate of Medical Research, IMS and SUM Hospital, Siksha "O" Anusandhan University, K8, Kalinganagar, Bhubaneswar, \\ Odisha, India \\ ${ }^{4}$ Department of Paediatrics, IMS and SUM Hospital, Siksha "O" Anusandhan University, K8, Kalinganagar, Odisha, India
}

\section{ABSTRACT}

\begin{abstract}
Introduction: The wide use of mobile phones in the world has raised the possibility of exposure to radiofrequency waves causing many side effects to the health of users, and even more in children.

Aim of the study: To study the impact of radiofrequency waves of mobile phones on the hearing of the children in a tertiary care teaching hospital.

Material and methods: We studied two groups of children of age less than 16 years. One group comprised 52 mobile phone users for more than one hour per day for more than one year, and the second group comprised 52 children who were non-users or used a mobile phone for less than one hour per day for less than one year. Results: The children using mobile phones for more than one hour (2-3 hours) per day for more than one year had $5 \mathrm{~dB}$ loss in $7.2 \%, 10 \mathrm{~dB}$ loss in $4.5 \%$, and 15 decibel loss in $2.5 \%$ of cases. There was a $5 \mathrm{~dB}$ loss in 7.9 and $10 \mathrm{~dB}$ in $5.5 \%$ of cases in those using mobiles $3-4$ hours per day. There was sensorineural hearing loss in $28.6 \%$ of the children and $3.6 \%$ in the control group.

Conclusions: This study did not show any significant hearing loss in children using mobile phones.
\end{abstract}

KEY WORDS:

mobile phone, children, sensorineural hearing loss, radiofrequency waves.

\section{INTRODUCTION}

The most effective and advanced communication device in this century is the mobile phone. Mobile phones are not only used by adults and qualified persons but also by children for playing games and many other forms of entertainment in. The mobile phone is nowadays a widely used electronic item in the world, affecting all ages of society. Nowadays children are a more noticeable group using mobile phones, and they are capable of using any advanced type of mobile phone. The increased use of mobile phones has now focused attention on the biological effects and health hazards due to radiofrequency exposure from mobile phones. Approximately $85 \%$ of Americans, $60 \%$ of the British, and more than $45 \%$ of Indians are using mobile phones [1]. The adverse effect due to mobile phone use is a global concern and affects people all over the world. The emission of radiofrequency radiation from mobile phones can affect the user over longer periods. Mobile phones receive and emit signals by

\section{ADDRESS FOR CORRRESPONDENCE:}

Santosh Kumar Swain, Department of Otorhinolaryngology, IMS and SUM Hospital, Bhubaneswar, Odisha,

India, e-mail: santoshvoltaire@yahoo.co.in 
using electromagnetic fields in the radiofrequency band. The Global System for Mobile communications (GSM) is presently the most widely used digital phone service operating at 900-1800 MHz frequency bands [2]. The inner ear is close to the mobile phone during any phone call, thus making it the most vulnerable organ. There are no regenerative properties of the hair cells in the cochlea, and so permanent damage may occur after prolonged exposure to radiofrequency waves by mobile phones. The hair cells of the cochlea are very sensitive to prolonged exposure to loud sound, and so the ear is at risk from mobile phones as well as the electromagnetic radiation emitted from the mobile phones. Keeping in the mind the hazards of the mobile phone, this study was conducted to investigate the association of mobile phone use and hearing loss in children.

\section{MATERIAL AND METHODS}

This study was conducted in a tertiary care teaching hospital of eastern India during a period of 3 years from January 2015 August to July 2017. There were 104 children

TABLE 1. Clinical presentations

\begin{tabular}{|l|c|c|c|c|}
\hline Symptoms & $\begin{array}{c}\text { Group I } \\
(n=52)\end{array}$ & $\begin{array}{c}\text { Group II } \\
(n=52)\end{array}$ & $\chi^{2}$ & $p$ \\
\hline aural block sensation & $12(23 \%)$ & $0 \%$ & 8.947 & 0.0014 \\
\hline decreased hearing & $4(7.69 \%)$ & $0 \%$ & 2.114 & 0.0730 \\
\hline tinnitus & $11(21.15 \%)$ & $0 \%$ & 8.123 & 0.0022 \\
\hline
\end{tabular}

TABLE 2. Hours of exposure to mobile phones in the study group

\begin{tabular}{|l|c|c|}
\hline $\begin{array}{l}\text { Hours of exposure } \\
\text { per day }\end{array}$ & $\begin{array}{c}\text { Number of children } \\
(n=52)\end{array}$ & Percentage (\%) \\
\hline 1 to 2 hours & 18 & 34.61 \\
\hline 2 to 3 hours & 23 & 44.23 \\
\hline 3 to 4 hours & 11 & 21.15 \\
\hline$x^{2}=6.29, p=0.043067$
\end{tabular}

TABLE 3. Hours of exposure per day and hearing loss

\begin{tabular}{|l|c|c|}
\hline $\begin{array}{l}\text { Hearing } \\
\text { loss }\end{array}$ & $\begin{array}{c}2-3 \text { hours/day } \\
\text { exposure }\end{array}$ & $\begin{array}{c}3-4 \text { hours/day } \\
\text { exposure }\end{array}$ \\
\hline $5 \mathrm{~dB}$ & $12 \%$ & $7.5 \%$ \\
\hline $10 \mathrm{~dB}$ & $4.4 \%$ & $4.5 \%$ \\
\hline $15 \mathrm{~dB}$ & $3.5 \%$ & $2.3 \%$ \\
\hline
\end{tabular}

TABLE 4. Years of exposure to mobile phones

\begin{tabular}{|l|c|c|}
\hline Group & $n$ & Mean \\
\hline I & 52 & 2.34 \\
\hline II & 52 & 0.11 \\
\hline
\end{tabular}

$t=59.9294, p=0.0001$ who participated in this study, with 52 mobile phone users and 52 were mobile phone non-users, with ages between 6 and 16 years. Mobile phone users $(n=52)$ were those who used a mobile phone for more than one year with minimum usage of more than one hour per day were included in our study. All the children underwent a questionnaire including the average duration of mobile use and different symptoms felt during and after the mobile phone use. All parents of the children gave informed consent prior to being included in the study. This study was approved by the Medical Ethics Committee of our Institute. Children with chronic suppurative otitis media, history of head injury, history of hearing loss, and those exposed to noisy environments were excluded from this study. All the children underwent detailed history taking with special emphasis on duration of usage, type of mobile, and hearing loss. Detailed general and systemic examinations along with thorough examination of the ear with an otoscope were done. At the outpatient department, all the children were assessed with tuning fork tests such as Rinne's, Weber's, and absolute bone conduction (ABC) tests. All the patients had undergone hearing assessment with pure tone audiometry. Pure tone audiograms were assessed for the type and degree of hearing loss.

\section{RESULTS}

This study was divided into two groups: 1 . Those children using mobile phones more than one hour per day for more than one year; 2 . No usage of mobile phones or using mobile only occasionally, i.e. less than one hour for less than one year. Chi-square and Student's t-tests were used for statistical analysis, and a $p$ value of less than 0.05 was considered as significant. There are three main symptoms found among patients: block sensation in the ear of 12 children (23\%), hearing loss in 4 children (7.69\%), and tinnitus in 11 children (21.15\%). Block sensation in the ear and tinnitus were statistically significant with $p$ value $<0.05$, whereas hearing loss was statistically insignificant $(p>0.05)$ (Table 1$)$. In this study, 18 (34.61\%) children had 1-2 hours of exposure to mobile phone per day, 23 (44.23\%) had 2-3 hours, and 11 (21.15\%) had 3-4 hours exposure to mobile phones per day. The $\chi^{2}$ value for hours of exposure to mobile phone was 6.29, and the $p$ value was 0.043067 , which was statistically significant (Table 2 ).

In our study, those using mobile phones for 2-3 hours per day, $5 \mathrm{~dB}$ loss was seen in 12\%, $10 \mathrm{~dB}$ loss in 4.4\%, and $15 \mathrm{~dB}$ loss in 3.5\%. There was $5 \mathrm{~dB}$ loss in $7.5 \%, 10 \mathrm{~dB}$ in $4.5 \%$ and $15 \mathrm{~dB}$ in $2.3 \%$ noted among those using mobile phones for 3-4 hours per day (Table 3). In group 1, the mean length of exposure was 2.34 years, whereas in group II it was 0.11 years with a $p$ value $<0.05$, which was statistically significant (Table 4 ). In this study, $24 \%$ of children using mobile phones for 2 years had sensorineural hearing loss, and $29 \%$ of those using mobile phones for 3 years had sensorineural hearing loss (Table 5). Continuous exposure was associated with minimal sensorineural 
hearing loss in our study, whereas intermittent exposure was seen in the control group. In group I, $19.23 \%$ and $15.38 \%$ of cases had minimal sensorineural hearing loss in the right ear and left ear, respectively, while in group II, $5.76 \%$ had sensorineural hearing loss in the only the right ear (Table 6 and 7).

\section{DISCUSSION}

Mobile phone use is very popular and almost indispensable in modern daily life. This is one of the fastest growing technological advancements in present times. Non-ionising electromagnetic radiofrequency radiation is commonly used in telecommunications like mobile phones, radio, TV, Wi-Fi, and radar. The exposure to this radiation is rapidly increasing in this decade, which has created interest in the possible harmful effects to health [3]. Sensitive individuals sometimes present dizziness, fatigue, headache, memory impairment, sleep disturbances, myalgia, anxiety, hearing loss, and tinnitus [4]. In our study, aural block sensation (23\%) followed by tinnitus (21.15\%) and decreased hearing (7.69\%) were the presentations among mobile users. Mobile phones have been used since 1983, and their use was estimated to include around 6 billion users in 2010 [5].

The mobile phone is one of the fastest-growing technological advancements in modern times. However, there is public concern about the possibility of health hazards of electromagnetic field (EMF) exposure from mobile phones. The prolonged use of mobile phones can be hazardous to the health of human life. The inner ear, particularly the cochlea, is the first important organ that usually receives the impact of the electromagnetic radiation due to its close locality and the delicate outer hair cells of the cochlea, which are highly vulnerable to acoustic injury in comparison to the other structures of the body. There are many studies comparing users and non-user of mobile phones, which showed some differences, even though the thresholds were within normal limits [6]. A study of mobile phone users concluded that hearing loss is associated with prolonged exposure to the electromagnetic fields that are generated from mobile phones [7]. Another study concluded that a 10-minute exposure to a radiofrequency field from a mobile phone had no effect on hearing loss [8]. Radiofrequency signals are emitted and received from the antenna of the mobile phone during phone calls. This may cause a high specific absorption rate (SAR) in the region of the ear in comparison to the other parts of the body. It can enter the tissue and is absorbed and converted into the heat [8].

The rapid use of wireless communications, particularly mobile phones, has created controversy regarding whether or not they pose a risk to human life. The mobile phone use among children is rapidly increasing nowadays. It is a great attraction for children due to various games and videos. The radiofrequency waves from the
TABLE 5. Duration of exposure (years) and sensorineural hearing loss

\begin{tabular}{|l|c|}
\hline Years of exposure & Sensorineural hearing loss $(5-15 \mathrm{~dB})$ \\
\hline 2 years & $24 \%$ \\
\hline 3 years & $29 \%$ \\
\hline
\end{tabular}

TABLE 6. Types of hearing loss in right ear

\begin{tabular}{|l|c|c|}
\hline Types of hearing loss & Group I & Group II \\
\hline normal $(n=91)$ & $42(80.76 \%)$ & $49(94.23 \%)$ \\
\hline $\begin{array}{l}\text { sensorineural hearing loss } \\
(n=13)\end{array}$ & $10(19.23 \%)$ & $3(5.76 \%)$ \\
\hline$x^{2}=4.3077, p=0.03794$ & & \\
\hline
\end{tabular}

TABLE 7. Types of hearing loss in left ear

\begin{tabular}{|l|c|c|}
\hline Types of hearing loss & Group I & Group II \\
\hline normal $(n=94)$ & $44(84.61 \%)$ & $52(100 \%)$ \\
\hline sensorineural hearing loss $(n=8)$ & $8(15.38 \%)$ & 0 \\
\hline$x^{2}=6.635, p=0.01$ &
\end{tabular}

mobile phones affect the health in two ways: thermal and non-thermal. The thermal or heating effect is due to prolonged holding of the mobile phone close the ear or body, and the non-thermal effect is due to radiation coming from the mobile phone. Mobile phones usually emit pulsed high frequency electromagnetic waves that can penetrate the skull and affect the brain and inner ear [9]. The electromagnetic waves may alter the electrical response due to acoustic stimuli. The prolonged and extensive exposure to microwaves radiating from mobile phones affects certain brain functions like electrochemistry, electrical activity, blood-brain barrier permeability, and the immune system [10]. The mobile phone radiofrequency waves are usually concentrated on the tissue nearer to the handset, which includes the auditory nerve [11]. The low-level radiofrequency radiation from the mobile phones sometimes gives rise to symptoms like headache, an unpleasant burning feeling, or dull ache at the temporal, occipital, or auricular area [12]. The biological effect due to mobile phone use depends on several factors like duration of irradiation, individualised nervous system, immune system, rate of absorption, and distribution of electromagnetic field energy by body tissue [13]. There have been reports of sensorineural hearing loss due to GSM mobile phone use [14]. Although little is known about mobile phones and their biological effect, this study shows that a higher degree of hearing loss is seen with long-term use of cellular phones. Therefore, it is advisable to avoid excess use of mobile phones, particularly among children. Mobile phones should be used only for short periods and only for important purposes.

Brainstem-evoked response audiometry (BERA) usually evaluates the hearing by using a signal averaging process and by measuring bioelectric events in response to auditory stimuli. The responses in the BERA can be 
recorded from the cochlea to the midbrain. These electric potentials are important tools for measuring hearing thresholds and neurological lesions. BERA is also an important tool for evaluating retro-cochlear lesions. BERA and pure tone audiometry are usually used for differentiating cochlear lesions from retro-cochlear pathologies. There are some studies regarding other health hazards from mobile phones. There is some controversy regarding brain lesions and tumours associated with mobile phone use [15]. Mobile phones generate electromagnetic radiation that is below the guidelines of the International Commission on Non-Ionising Radiation Protection (ICNIRP) [16]. The radiofrequencies emitted from mobile phones are not energetic enough to destabilise the electron configuration within DNA. So, there is a direct link between radiofrequency exposure and genotoxic side effects like DNA mutations [16]. This study suggests several recommendations for children using mobile phones, which are: to set the lowest volume while playing mobile games and phone calls, having a short conversation period, using a hands-free device, and choosing mobile phones with low electromagnetic field emissions.

\section{CONCLUSIONS}

This study does not show any significant correlation between mobile phone use and hearing loss among children. The children using a mobile phone for more than two hours showed mild hearing loss of around 10-15 dB, but $0-25 \mathrm{~dB}$ hearing loss is taken as normal. Here we suggest a long-term follow up study is required among the children using prolonged period mobile users. The authors suggest mobile phones should be used only for short periods and for essential purposes.

\section{DISCLOSURE}

The authors declare no conflict of interest.

\section{REFERENCES}

1. Hegde MC, Shenoy VS, Kamath PM, et al. Mobile phones and effects on hearing. Indian J Otol 2013; 19: 122-126.

2. Mostafapour SP, Lahargoue K. Noise induced hearing loss in young adults. Laryngoscope 1998; 108: 1832-1839.

3. Bortkiewicz A, Gadzicka E, Szymczak W, et al. Changes intympanic temperature during the exposure to electromagneticfields emitted by mobile phone. Int J Occup Med Environ Health 2012; 25: 145-150.

4. Küçer N, Pamukçu T. Self-reported symptoms associated with exposure to electromagnetic fields: a questionnaire study. Electromagn Biol Med 2014; 33: 15-17.

5. Velayutham P, Govindasamy GK, Raman R, et al. High-Frequency Hearing Loss Among Mobile Phone Users. Indian J Otolaryngol Head Neck Surg 2014; 66: 169-172.

6. Shayani-Nasab M, Safavi Naiianni SA, Fathol Alolomi MR, et al. Effects of mobile telephones on hearing. Acta Medica Iran 2006; 44: $46-48$.
7. Oktay MF, Dasdag S. Effects of intensive and moderate cellular phone use on hearing function. Electromagn Biol Med 2006; 25: 13-21.

8. Ozturan O, Erdem T, Miman MC, et al. Effects of mobile telephone's electromagnetic field on hearing. Acta Otolaryngol 2002; 122: 289-293.

9. Eulitz C, Ullsperger P, Freude G, et al. Mobile phones modulate response patterns of human brain activity. Neuroreport 1998; 9: 3229-3232.

10. Reiser H, Dimpfel W, Schober F. The influence of electromagnetic fields on human brain activity. Eur J Med Res 1995; 1: 27-32.

11. Lonn S, Ahlbom A, Hall P, et al. Mobile phone use and risk of acoustic neuroma. Epidemiology 2004; 15: 653-659.

12. Valberg P, Deventer T, Repacholi M. Workgroup Report: Base stations and Wireless Networks-Radiofrequency (RF) exposure and Health consequences. Environ Health Perspect 2007; 115: 416-424.

13. Ozturan O, Erden T, Miman MC, et al. Effects of electromagnetic field of mobile telephones on hearing. Acta Otolaryngol 2002; 112: 289-293.

14. Al-Dousary SH. Mobile phone induced sensorineural hearing loss. Saudi Med J 2007; 28: 1283-1286.

15. Dubey RB, Hanmandlu M, Gupta SK. Risk of brain tumors from wireless phone use. J Comput Assist Tomogr 2010; 34: 799-807.

16. Ahlbom A, Green A, Kheifets L, at al. International Commission for Non-Ionizing Radiation Protection Standing Committee on Epidemiology. Epidemiology of health effects of radiofrequency exposure. Environ Health Perspect 2004; 112: 1741-1754. 